\title{
Compensation of ACE2 Function for Possible Clinical Management of 2019-nCoV-Induced Acute Lung Injury
}

\author{
Yuntao $\mathrm{Wu}^{1}$ (1)
}

Received: 1 February 2020 / Accepted: 3 February 2020 / Published online: 7 February 2020

(c) Wuhan Institute of Virology, CAS 2020

The 2019-nCoV viral infection causes clusters of severe respiratory illness such as an acute respiratory distress syndrome (ARDS) similar to that caused by SARS-CoV (severe acute respiratory syndrome coronavirus) (Huang et al. 2020). Both 2019-nCoV and SARS-CoV use the same receptor, ACE2 (angiotensin converting enzyme 2), to infect cells ( $\mathrm{Li}$ et al. 2003; Zhou et al. 2020). ACE2 is one of the central enzymes in the renin-angiotensin system (RAS) (Donoghue et al. 2000; Imai et al. 2010; Tipnis et al. 2000) that regulates blood pressure, fluid and electrolyte balance, and systemic vascular resistance (Paul et al. 2006; Zimmerman and Dunham 1997).

In the lungs, activation of local pulmonary RAS can affect the pathogenesis of lung injury via multiple mechanisms, such as an increase in vascular permeability and alterations of alveolar epithelial cells (Kuba et al. 2006; Specks et al. 1990). Activation of pulmonary RAS involves renin, the initial enzyme of the RAS activation cascade (Fig. 1). Renin cleaves angiotensinogen, a globular protein, to generate angiotensin I (Ang I, a decapeptide hormone). The angiotensin-converting enzyme (ACE) then converts Ang I to angiotensin II (Ang II, an octapeptide hormone). Ang II exerts vasoactive effects through binding to its receptors, the angiotensin II type I (AT1) and type II (AT2) receptors.

ACE2 is a homologue of ACE and plays a pivotal role in balancing responses initiated from ACE (Donoghue et al. 2000; Imai et al. 2010; Tipnis et al. 2000). ACE2 hydrolyses Ang I to generate Ang-(1-9). ACE2 also hydrolyses Ang II to generate Ang-(1-7), which binds to the G-protein coupled receptor MAS (Reudelhuber 2005; Santos et al. 2003) to antagonize many of the Ang II-mediated effects.

Yuntao $\mathrm{Wu}$

ywu8@gmu.edu

1 National Center for Biodefense and Infectious Diseases, School of Systems Biology, George Mason University, Manassas, VA 20110, USA
Overall, ACE2 functions as a counter-regulatory enzyme by decreasing local Ang II concentrations.

In the lungs, RAS activity, ACE, and Ang II are intrinsically high, and ACE2 activities are also highly elevated to regulate the balance of Ang II/Ang-(1-7) levels (Kuba et al. 2006; Specks et al. 1990). High levels of Ang II can lead to increases in vascular permeability and pulmonary oedema (Fyhrquist and Saijonmaa 2008; Marshall 2003; Marshall et al. 2004). In mouse models of acute respiratory distress syndrome, ACE2 knockout mice displayed more severe symptoms, while overexpression of ACE2 had some protective effects (Imai et al. 2005). In SARS-CoV infection of mice, both viral replication and the viral spike protein alone have been shown to selectively reduce ACE2 but not ACE expression (Kuba et al. 2005). In addition, SARS-CoV also induces rapid downregulation of ACE2 from the cell surface (Glowacka et al. 2010; Wang et al. 2008) and the release of catalytically active ACE2 ectodomains (Haga et al. 2008; Jia et al. 2009; Lambert et al. 2005). These results suggest that the physiological balance between ACE/ACE2 and Ang II/Ang(1-7) is likely disrupted by SARS-CoV viral infection. This virus-mediated effect likely has a pathogenic role in lung injury (Imai et al. 2008; Kuba et al. 2006; Yamamoto et al. 2006). Indeed, injection of SARS-CoV spike protein into mice led to a significant increase in Ang II levels in the lung tissue and exacerbated acid-induced acute lung injury (Kuba et al. 2005). Results from these previous animal studies suggested a possible mechanism of how SARS$\mathrm{CoV}$ infection may cause severe lung failure, which is likely mediated through high levels of Ang II resulting from the inhibition of ACE2 by the viral spike protein. Given that the spike protein of 2019-nCoV interacts with ACE2 as does the spike protein of SARS-CoV, it is possible that the pathogenic mechanism may be shared between these two viruses. Based on this assumption, compensation of ACE2 and balancing ACE/ACE2 function may be a way to alleviate virus-induced severe lung injury. 


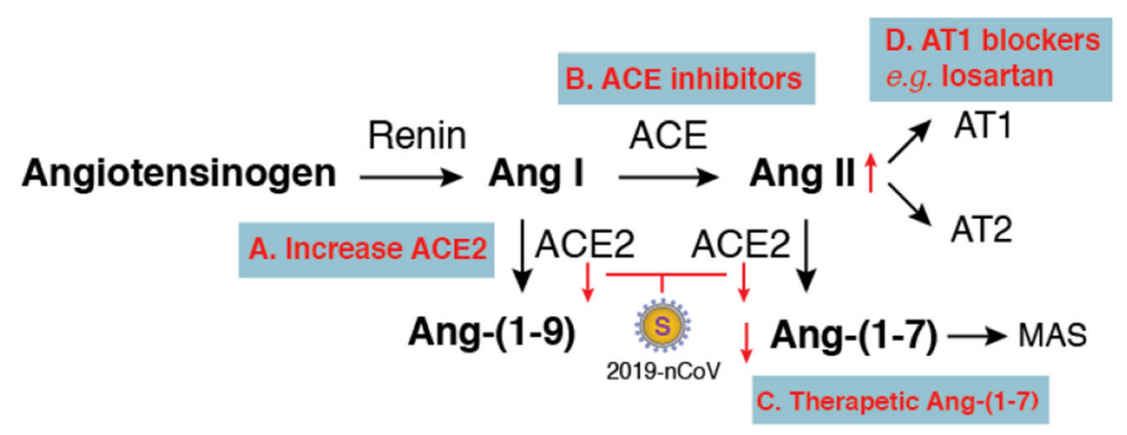

Fig. 1 Potential therapeutics for 2019-nCoV-induced lung injury based on balancing the renin-angiotensin system (RAS). Activation of the RAS cascade involves Renin cleaves angiotensinogen to generate Ang I, which is then converted to Ang II by ACE. Ang II binds to its receptors (AT1 and AT2) to exert local and systemic effects such as vasoconstriction and promotion of the release of aldosterone. ACE2 functions as a counter-regulatory enzyme for

There are several potential therapeutic approaches that may be tested or developed (Fig. 1). First, therapies to increase ACE2 expression may be developed in the future, through direct injection of recombinant ACE2 protein, which has been shown to protect mice from severe acute lung injury (Imai et al. 2005), and by delivering therapeutic vectors expressing high levels of ACE2 directly into lung tissues to overcome virus-induced ACE2 deficiency. Second, certain ACE inhibitors such as lisinopril may be used to balance the ACE/ACE2 function. In addition, therapeutic Ang-(1-7) heptapeptide may be delivered to activate its receptor MAS and to counteract the activities of Ang II. Furthermore, drugs blocking Ang II receptors may also be tested. In particular, the type I, but not type II, Ang II receptor has been shown to promote disease pathogenesis by inducing lung oedemas and impairing lung function (Imai et al. 2005). Thus, a type I Ang II receptor blocker such as losartan could be tested for alleviating 2019-nCoVinduced lung injury.

In sum, at present, there are no effective drugs for the treatment of 2019-nCoV-induced lung injury, which can often lead to lethal lung failure in patients. This perspective is intended to stimulate discussions about possible pathogenic mechanisms, based on the interaction of the virus with its receptor ACE2, so that rational therapies can be developed. Although ACE is regarded as the primary Ang II-converting enzyme, another enzyme, chymase, is also involved in converting Ang II in certain pathological conditions that may need attention (Fyhrquist and Saijonmaa 2008; Lindberg et al. 1997). In addition, coronavirus pathogenesis is a highly complex process (Lo et al. 2006), and much of the needed detail in host-pathogen interaction in 2019-nCoV infection awaits investigation. It also remains to be clinically tested whether some of these potential treatments, as proposed here, can be effective or balancing responses initiated from ACE. ACE2 hydrolyses Ang I and Ang II to generate Ang-(1-9) and Ang-(1-7). Ang-(1-7) binding to the MAS receptor antagonizes Ang II-mediated actions. SARS-CoV and 2019-nCoV use ACE2 as the entry receptor. Inhibition of ACE2 expression or downregulation of surface ACE2 by these coronaviruses may disrupt function balances between ACE/ACE2, which may be alleviated by different approaches (from $\mathbf{A}$ to $\mathbf{D}$ ).

beneficial in the management of 2019-nCoV-induced lung injury.

Acknowledgements The author wishes to thank Jennifer Guernsey for editorial assistance.

\section{Compliance with Ethical Standards}

Conflict of interest The authors declare that they have no conflict of interest.

Animal and Human Rights Statement This article does not contain any studies with human or animal subjects performed by any of the authors.

\section{References}

Donoghue M, Hsieh F, Baronas E, Godbout K, Gosselin M, Stagliano N, Donovan M, Woolf B, Robison K, Jeyaseelan R, Breitbart $\mathrm{RE}$, Acton S (2000) A novel angiotensin-converting enzymerelated carboxypeptidase (ACE2) converts angiotensin I to angiotensin 1-9. Circ Res 87:E1-E9

Fyhrquist F, Saijonmaa O (2008) Renin-angiotensin system revisited. J Intern Med 264:224-236

Glowacka I, Bertram S, Herzog P, Pfefferle S, Steffen I, Muench MO, Simmons G, Hofmann H, Kuri T, Weber F, Eichler J, Drosten C, Pöhlmann S (2010) Differential downregulation of ACE2 by the spike proteins of severe acute respiratory syndrome coronavirus and human coronavirus NL63. J Virol 84:1198-1205

Haga S, Yamamoto N, Nakai-Murakami C, Osawa Y, Tokunaga K, Sata T, Yamamoto N, Sasazuki T, Ishizaka Y (2008) Modulation of TNF-alpha-converting enzyme by the spike protein of SARS$\mathrm{CoV}$ and ACE2 induces TNF-alpha production and facilitates viral entry. Proc Natl Acad Sci USA 105:7809-7814

Huang C, Wang Y, Li X, Ren L, Zhao J, Hu Y, Zhang L, Fan G, Xu J, $\mathrm{Gu}$ X et al (2020) Clinical features of patients infected with 2019 novel coronavirus in Wuhan, China. Lancet. https://doi.org/10. 1016/S0140-6736(20)30183-5

Imai Y, Kuba K, Rao S, Huan Y, Guo F, Guan B, Yang P, Sarao R, Wada T, Leong-Poi H, Crackower MA, Fukamizu A, Hui CC, Hein L, Uhlig S, Slutsky AS, Jiang C, Penninger JM (2005) 
Angiotensin-converting enzyme 2 protects from severe acute lung failure. Nature 436:112-116

Imai Y, Kuba K, Penninger JM (2008) The discovery of angiotensinconverting enzyme 2 and its role in acute lung injury in mice. Exp Physiol 93:543-548

Imai Y, Kuba K, Ohto-Nakanishi T, Penninger JM (2010) Angiotensin-converting enzyme 2 (ACE2) in disease pathogenesis. Circ J 74:405-410

Jia HP, Look DC, Tan P, Shi L, Hickey M, Gakhar L, Chappell MC, Wohlford-Lenane C, McCray PB Jr (2009) Ectodomain shedding of angiotensin converting enzyme 2 in human airway epithelia. Am J Physiol Lung Cell Mol Physiol 297:L84-L96

Kuba K, Imai Y, Rao S, Gao H, Guo F, Guan B, Huan Y, Yang P, Zhang Y, Deng W et al (2005) A crucial role of angiotensin converting enzyme 2 (ACE2) in SARS coronavirus-induced lung injury. Nat Med 11:875-879

Kuba K, Imai Y, Penninger JM (2006) Angiotensin-converting enzyme 2 in lung diseases. Curr Opin Pharmacol 6:271-276

Lambert DW, Yarski M, Warner FJ, Thornhill P, Parkin ET, Smith AI, Hooper NM, Turner AJ (2005) Tumor necrosis factor-alpha convertase (ADAM17) mediates regulated ectodomain shedding of the severe-acute respiratory syndrome-coronavirus (SARS$\mathrm{CoV}$ ) receptor, angiotensin-converting enzyme-2 (ACE2). J Biol Chem 280:30113-30119

Li W, Moore MJ, Vasilieva N, Sui J, Wong SK, Berne MA, Somasundaran M, Sullivan JL, Luzuriaga K, Greenough TC, Choe H, Farzan M (2003) Angiotensin-converting enzyme 2 is a functional receptor for the SARS coronavirus. Nature 426:450-454

Lindberg BF, Gyllstedt E, Andersson KE (1997) Conversion of angiotensin I to angiotensin II by chymase activity in human pulmonary membranes. Peptides 18:847-853

Lo AW, Tang NL, To KF (2006) How the SARS coronavirus causes disease: host or organism? J Pathol 208:142-151

Marshall RP (2003) The pulmonary renin-angiotensin system. Curr Pharm Des 9:715-722

Marshall RP, Gohlke P, Chambers RC, Howell DC, Bottoms SE, Unger T, McAnulty RJ, Laurent GJ (2004) Angiotensin II and the fibroproliferative response to acute lung injury. Am J Physiol Lung Cell Mol Physiol 286:L156-L164

Paul M, Poyan Mehr A, Kreutz R (2006) Physiology of local reninangiotensin systems. Physiol Rev 86:747-803

Reudelhuber TL (2005) The renin-angiotensin system: peptides and enzymes beyond angiotensin II. Curr Opin Nephrol Hypertens 14:155-159

Santos RA, Simoes e Silva AC, Maric C, Silva DM, Machado RP, de Buhr I, Heringer-Walther S, Pinheiro SV, Lopes MT, Bader M, Mendes EP, Lemos VS, Campagnole-Santos MJ, Schultheiss HP, Speth R, Walther T (2003) Angiotensin-(1-7) is an endogenous ligand for the $G$ protein-coupled receptor Mas. Proc Natl Acad Sci USA 100:8258-8263

Specks U, Martin WJ 2nd, Rohrbach MS (1990) Bronchoalveolar lavage fluid angiotensin-converting enzyme in interstitial lung diseases. Am Rev Respir Dis 141:117-123

Tipnis SR, Hooper NM, Hyde R, Karran E, Christie G, Turner AJ (2000) A human homolog of angiotensin-converting enzyme. Cloning and functional expression as a captopril-insensitive carboxypeptidase. J Biol Chem 275:33238-33243

Wang S, Guo F, Liu K, Wang H, Rao S, Yang P, Jiang C (2008) Endocytosis of the receptor-binding domain of SARS-CoV spike protein together with virus receptor ACE2. Virus Res 136:8-15

Yamamoto K, Ohishi M, Katsuya T, Ito N, Ikushima M, Kaibe M, Tatara Y, Shiota A, Sugano S, Takeda S, Rakugi H, Ogihara T (2006) Deletion of angiotensin-converting enzyme 2 accelerates pressure overload-induced cardiac dysfunction by increasing local angiotensin II. Hypertension 47:718-726

Zhou P, Yang X-L, Wang X-G, Hu B, Zhang L, Zhang W, Si H-R, Zhu Y, Li B, Huang C-L, Chen H-D, Chen J, Luo Y, Guo H, Jiang R-D, Liu M-Q, Chen Y, Shen X-R, Wang X, Zheng X-S, Zhao K, Chen Q-J, Deng F, Liu L-L, Yan B, Zhan F-X, Wang Y-Y, Xiao G-F, Shi Z-L (2020) A pneumonia outbreak associated with a new coronavirus of probable bat origin. Nat. https://doi.org/10.1038/s41586-020-2012-7

Zimmerman BG, Dunham EW (1997) Tissue renin-angiotensin system: a site of drug action? Annu Rev Pharmacol Toxicol 37:53-69 